\title{
Quality Research in Higher Education Institutions in Oman: Some Views of Teacher Researchers
}

\author{
Ahmed Ali Saleh Al Ajmi (Correspondence author) \\ Department of English Language \& Literature (DELL), Rustaq College of Applied Sciences, Oman \\ E-mail: ahmed.ali.alajmi@gmail.com \\ Holi Ibrahim Holi Ali \\ School of Education \& Professional Development, University of Huddersfield, UK
}

Doi:10.7575/aiac.alls.v.6n.3p.55

URL: http://dx.doi.org/10.7575/aiac.alls.v.6n.3p.55
Received: 05/02/2015

Accepted: 15/03/2015

\begin{abstract}
Academic research remains a prime source of knowledge and innovation for higher education institutions (HEIs) that strive to grow, expand and develop their academic reputations and standards. Yet, research informs teaching practices, shapes social changes and it has financial outcomes for HEIs. Therefore, it is imperative to develop institutional policies and strategies for promoting and sustaining quality research in HEIs in Oman. There are a number of international frameworks and models which have been developed to measure research quality in HEIs around the world. For example, bibliometrics were used to assess research quality in HEIs in the UK because bibliometric data can provide a number of component variables. An appropriate bibliometric model may include components such as output volume, diversity of outputs, citation volume, journal impact factor and average citations per publication, etc. Moreover, other popular examples of models for assessing research quality are Multidimensional Research Assessment Matrix (MRAM) used in Europe and the UK's Research Assessment Exercise (RAE). However, neither of the above mentioned models is adopted by HEIs in Oman. Thus, the current study is an attempt to explore some institutional, international, logistic and pragmatic factors that impact academic research and publication quality, review popular international research quality assessment models and explore the possibility of applying them in the Omani context. To achieve the study objectives, 20 teacher researchers were surveyed and the findings and recommendations were presented.
\end{abstract}

Keywords: Quality Research, HEIs in Oman, International Models, Factors, Teacher Researchers' Views

\section{Introduction}

As higher education (HE) expands, the public expects universal access to HEIs and more quality in HEIs (Chang, Nyeu and Chang, 2014). Higher education in Oman has expanded after 1970 and now there are more than 62 public and private HEIs in Oman. The expansion of HEIs in Oman provides Omani citizens with opportunities to access HEIs as well as providing them with a variety of majors among which students can choose. Yet, it is important to ensure quality in such HEIs by considering quality of the progrmmes they offer to students and the research they produce. Chang et al (2014) point out that the increase in the number of HEIs and students does not necessarily improve educational quality. Further, Wu (2008) indicates that quality in some of HEIs has been negatively affected due to the increase in the number of students and HEIs and lack of quality research. It is of utmost importance to strike a balance between teaching and research in HEIs to ensure balance between quality of the HEIs programmes offered and quantity of enrolled students (Chang et al., 2014). The quality of teaching in HEIs is strongly connected to research which plays a significant role in shaping the teaching and learning process (Mahmood, 2011). That is, the idea of research-teaching nexus should be of mission goal for all HEIs (Hattie \& March, 1996). Therefore, it is vital to ensure quality of research in HEIs by adopting international models used in assessing research quality and address factors which could affect the quality of academic research and publications. To realize this aim, this present study reviews some existing international models and explores factors that may affect the quality of research in HEIs in Oman such as institutional factors, logistic factors, international factors and pragmatic factors. Further, some possible ways for promoting quality research in the growing Omani HEIs were suggested.

\subsection{Statement of the Problem}

Research quality in HEIs in Oman needs to be closely looked at as there are concerns about how quality research is assessed and to what extent research contributes to the development of policies and practices in HEIs in Oman. In fact, Brennan and Teichler (2008, p. 261) point out that higher education research "generally lacks a stable institutional basis within higher education institutions". That is, there is usually a lack of link between research and teaching practices. This study is motivated by the fact that there is paucity in research with regard to quality research and the factors that may impact it in Oman. Many teachers and practitioners have been conducting research, publishing academic papers and seeking grants from agencies but the quality of these publications and papers, the factors that may impact them and 
models which can be used to assess them have not been investigated yet. Therefore, this small-scale study strives to explore the factors that affect quality of research in the Omani HEIs and to find out how quality in research can be realized and sustained within Omani HEIs.

\section{Theoretical Underpinnings}

\subsection{Factors Affecting Quality Research and Academic Publications in HEIs}

Quality control in HEIs has become a core and growing issue in their mission and visions. Therefore, most of the HEIs have established their quality assurance units and departments to improve and control quality teaching, learning and research. To enhance quality in HEIs research and system, Mok and Wang (2008) suggest that HEIs should introduce competitive funding schemes and allocate resources to universities based on the quality of faculty research and instruction. Funding sources, according Chang et al (2014), can be students' fees, income from continuing education programmes, industry collaboration, and rental of building or facilities, gifts and donations, income generated from savings and other financial activities. Policymakers therefore should reevaluate HEIs' budgets in order to promote academic efficiency and increase the international competitiveness of their HE system (Chou, 2008). There are a number of factors which could affect research and academic publication quality. These factors are as follow: Firstly, institutional such as availability of resources, internet connectivity, research funds, staff awareness of what makes quality research, importance of research, etc. Secondly, international factors such as quality of journals, impact factor issues, citation volume, peer-review issues, quality of editorial boards, trustworthiness of research, research findings utility, etc. Finally, HEIs should consider pragmatic factors which include the purpose of the research, research for personal growth, nexus between research and teaching that informs teaching, etc. Therefore, teacher researchers' views were explored to answer the study questions.

\subsection{Existing Paradigms or Models for Assessing Quality Research in HEIs}

There are a number of research assessment paradigms and models which could be used to control research quality, two of them will be discussed here. A popular one is Research Assessment Exercise (RAE) which was made collaboratively by the Higher Education Funding Council for England (HEFCE), the Higher Education Funding Council for Wales (HEFCW), the Scottish Funding Council (SFC) and the Department for Employment and Learning (DEL), Northern Ireland. RAE is one of the popular international research evaluation systems that have been able to find a way of assessing quality of research (Cabral \& Huet, 2014). According to Barker (2007, p. 3; cited in Cabral \& Huet, 2014) "RAE represents one of the most institutionalized forms of research evaluation in the OECD [Organisation for Economic Co-operation and Development] economies". It is an ex-post informed peer system and which aims to produce quality profiles based on: clarity, creditability, neutrality, consistency, efficiency, continuity, parity and transparency of research (HEFCE, 2008). Cabral and Huet (2014) point out that RAE is constructed around three quality criteria which are: rigor, originality and significance. They also underline the fact that RAE's key characteristic is peer review reading-based evaluation. Despite the positive side RAE has, Furlong and Oancea (2005) state that RAE should have an equal value to basic research, strategic research, applied research and practice-oriented research. According to them, policymakers' expectations are that research should help to find solutions to entire education problems and therefore there are persistent mutual reservations about it: (1) many policymakers and teachers feel that researchers lack accountability and that (2) some researchers are concerned that the research process is being affected by a pragmatic agenda which devalue the importance of theoretical knowledge. A new four-dimension model to assess research quality was then created (see Furlong \& Oancea, 2005, p. 15). The first dimension is epistemic which focuses on methodological and theoretical robustness including trustworthiness, explicitness, priority and paradigm-dependent criteria. The second dimension is the technological dimension which includes purposivity, salience, accessibility, concern for enabling impact and flexibility. Third, the capacity development and value for people dimension concerns plausibility, partnership and collaboration, reflexivity and criticism, receptiveness, transformation and personal growth. The last dimension is called economic which involves marketability, competitiveness, cost-effectiveness, auditability, feasibility and originality.

Another paradigm for assessing research quality is bibliometrics which are, according to Adams (2009, p. 23), "indicators of research performance based on data associated with journal articles" and publications. According to Haustein and Lariviere (2015), bibliometrics trace back to the $20^{\text {th }}$ century as librarians used them as an instrument for journal collection development. Bibliometrics are mainly used by public sectors and other funding organisations because of their large-scale applicability, lower costs, time saving features and effectiveness (Weingart, 2005). Bibliometric data can provide a number of component variables. An appropriate bibliometric model may include components such as output volume, diversity of outputs, citation volume, journal impact factor and average citations per publication (Adams, 2009). Yet, it is important to highlight that bibliometrics may be misused at the level of individuals or groups. Haustein and Lariviere $(2015$, p. 130) point out that researchers and journal editors may manipulate the outcomes of indicators and the consequence is "changes of publication and citation behavior". They indicate that the more use of bibliometrics indicators to assess research outputs as criteria for funding purposes, the more "unethical behavior" takes place. Therefore, it is imperative for HEIs in Oman to adopt one of these models or integrate them and consider all the factors which could affect research quality in their institutions. 
The aim of research productivity is to contribute to knowledge and improve teaching / learning process. Therefore, The Research Council (TRC) was established in June 2005 by a Royal Decree in Oman to provide grants, promote research productivity and assure and maintain quality research in HEIs and among scholars to solve the community problems which demand rigorous investigation and inquiry. Its main aims are to promote and encourage the application of research findings by considering the needs of the Omani context. TRC employs two sets of criteria to evaluate the excellence and relevance for an open research grant (ORG). According to the ORG guidelines manual (2014, p. 20), the criteria for assessing the excellence of submissions include: novelty and originality, comprehensiveness of literature review which justifies the research proposal, clarity of research statement and research approaches used, significance of the intended research project, research goals and objectives, and the qualifications and skills the researchers have. The criteria for assessing the relevance of a submission to ORG include: specification of resources, relevance to Oman's socioeconomic development, involvement of young Omani researchers, collaboration with other institutions, addressing more than one academic discipline and research efficiency and efficacy. TRC criteria should be adopted along with the other suitable international models by HEIs in Oman to maintain research quality and to get appropriate funds. TRC guidelines and criteria should be integrated with popular existing models to promote research quality in HEIs in Oman.

\section{Objectives of the Study}

The current study is set out to explore teacher researchers' views about what makes quality research and academic publications; to investigate the factors that may affect quality of research in Omani HEIs; to review some existing quality assessment models which have been used to assess quality research worldwide, and to find out some possible ways for promoting quality research in Omani HEIs.

\subsection{Research Questions}

1. What are the teacher researchers' views about quality research?

2. What are some factors that may affect quality of research in HEIs in Oman?

3. How can quality research in the Omani HEIs be promoted by adopting existing international quality research assessment models?

\section{Methods}

The research design underlining this small-scale study is an exploratory one. The purpose of this paper is to investigate and demonstrate teacher researchers' in HEIs views about what makes quality research and publications; and what are the factors that may impact research quality; what are the existing popular models for assessing research quality; and how can quality research be achieved and promoted. Convenient sampling was adopted based on teacher researchers' availability and accessibility. Twenty teacher researchers were surveyed and existing research assessment models were reviewed. The survey is made up of seven open-ended questions, which aimed to generate rich and extended response from the participants. The data were analyzed using emerged themes and thematic unity. Most the participants are English language teacher researchers and professionals and they have substantial experiences in research and academic publications.

\section{Survey-based Analysis}

There are some key preliminary findings which are worth reporting as per the study questions:

1. What are the teacher researchers' views about quality research? In response to this question, some teacher researchers believed that: I think there are different factors, for example, university or journal's instructions, the research questions should be stated clearly and why these questions are important, the study methods must be reported with evidence, and there should a reliable data source and methodology. Quality of research: sound methodology from start to finish, good sampling, applied research questions. Quality publication: well-organized, clear, findings are not over-interpreted, well-framed rationale; and it should be published in reputable journals and should be relevant to the needs of the country. Quality research should have good scientific method or objectivity. It should include all aspects of study design focusing on what kind of questions you find worth investigating, the research method you adopt, and the evidence by which you evaluate results.

Another teacher researcher reported: Well defined problem, robust research methodology, and absence of hidden agenda. QUALITY PUBLICATION: Novelty of topics, Easy to follow layout of presentations, focus on quality of research rather than on prolificacy of the author.

\section{What are the factors that may affect quality of research in HEIs in Oman?}

In response to this question, here are some extracts from the open-ended questions which summarize the factors that may affect research quality in HEIs in Oman.

Institutional factors: A teacher researcher believed: These can have negative impacts on research quality and publication: Pressure on academics to produce research even prematurely, time constrains and red tapes regarding access to participants/subjects, and lack of well-organized forums/sessions/seminars for researchers' output. 
Another teacher said: I think institutions should encourage and equip researchers and then send the best ones to do their studies in reputed universities, less teaching load, lack of support (financial, administrative), Lack of proper research training for teachers and students, staff members not sure of the range of methods taught or the provision of analysis software, both are very important, acknowledgement of the research activity, provision of support (financial \& resources), flexible promotion opportunities, and the quality of expertise in a given institution and their level of collaboration.

International factors: The hegemony exercised by English language in the international arena in barring the recognition of any research conducted in Arabic (for example). I think a number of (Arab) scholars/researchers can research interesting issues, but the language barrier interdicts access to publication and dissemination.

A teacher researcher said: Researchers should do their research in top-ranked international universities; there is a hesitance to approach sensitive topics, the challenge of many not knowing about Omani culture, the need to collaborate with established resources in the field, the need for speedy publication, and the availability of joint teaching and research (collaboration of Omani HEIs and other HEIs).

Logistical factors: Government should spend money on researchers and research and the return is fast and worth spending, financial support, - time, access to proper materials including software (see above) and online library database, timely appraisal and applications for support, giving permission to use facilities in the academic institutions, giving permission to acquire data from original sources, and availability of research on university policy and solutions to that may face researchers.

\section{How can quality research in the Omani HEIs be achieved and promoted?}

A teacher researcher reported: Funding of projects, encouraging research in Arabic (with constant support in the area research methodology), establishing refereed (Arabic) research journals, and indigenization of research and research methodology.

Another teacher said: create peer reviewing committee (at institutional level), prepare a so called gold standard publication checklist for HE teachers, provide financial support, allow for flexible and light teaching load, provide incentives for well research achievers, allow for promotion of good researchers, support for each other (research teams), ongoing professional development, ability to "buy out" a teaching load to conduct research, publication should be promoted in many ways like other university lecturers must receive some credits, academic publications can be improved by following journals' instructions and publication can positively impact Omani HE by conducting quality research studies and support them according to the quality assurance rules and regulations.

A teacher researcher believed: Researchers in Ivory towers can produce educational research that may be of less relevance to teachers. The more relevant research can be produced as a result of reflection (by teachers) in action, before action, and after action. The bureaucracy is one of the hindrances that reduce the motivation for doing research/ publications and to be frank, institutional polices are not up to the level and the current institutional polices do not reward quality publications.

Another teacher reported: It is very important to have nexus between research and teaching. Because when the research is based on teaching it will provide hands on implications for other teachers.

To realize the main objectives of this small scale study, teacher researchers believed that quality research could be affected by institutional, international, and logistical factors. Therefore, teacher researchers' suggestions for promoting quality research in HEIs in Oman were presented in table (2). Moreover; some of the popular international existing models for assessing research quality were reviewed and discussed. In the light of the above mentioned responses, it could be argued that institutional, international and logistical factors can impact research quality and therefore, they should be considered by Omani HEIs along with other existing research assessment paradigms in order to promote quality research.

\section{Summary of Key Findings}

\subsection{Summary of Teacher Researchers' Views about What Makes Quality Research}

Table 1 . Teacher researchers' views about quality research

Summary of Teacher Researchers' Views about Quality Research

- Sound methodology

- Good sampling

- Applied research questions

- Well-organized and appropriate research design

- $\quad$ Findings are not over-interpreted

- Well-formed rationale

- Having research skills and abilities

- Published in reputable \& refereed journals

- Research questions are worth investigating

- Addressing real problem not for the sake of increasing research publication numbers

- Topicality with the state-of-the art trends in the area

- Based on personal interest \& commitment 
Table 2. Summary for the key factors which may affect research quality based on the data collected via the survey

\begin{tabular}{|c|c|c|}
\hline No & Factors & Summary \\
\hline 1 & Institutional & $\begin{array}{ll}\text { - } & \text { Pressure from institutions on academic staff to } \\
\text { - } & \text { produce research } \\
\text { - } & \text { Well-organized workshops \& seminars on research- } \\
\text { - } & \text { Telated topics } \\
\text { - } & \text { Finanching load and heavy timetables } \\
\text { - } & \text { Proper research training } \\
\text { - } & \text { Acknowledgement of research activities and } \\
\text { - } & \text { Institutional pressure } \\
\text { - } & \text { Linking publication with promotion } \\
\end{array}$ \\
\hline 2 & International & 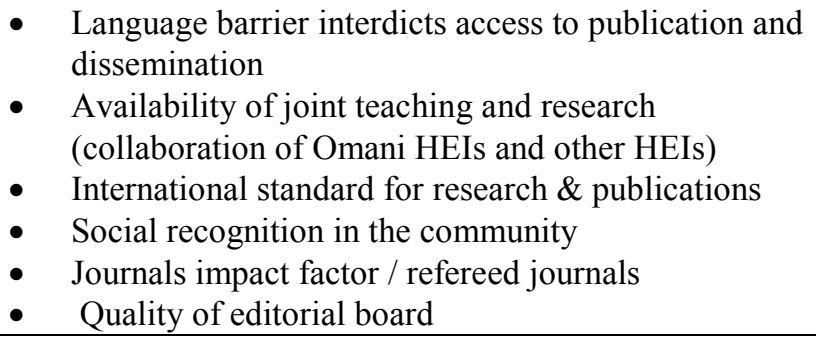 \\
\hline 3 & $\begin{array}{c}\text { Logistical, pragmatic factors \& } \\
\text { significant others }\end{array}$ & $\begin{array}{l}\text { - } \quad \text { Proper access to proper materials including software } \\
\text { - } \quad \text { Good library \& free access to data database } \\
\text { - } \quad \text { Availability of research in university policy and } \\
\text { - } \quad \text { colutions to problems that may face researchers } \\
\text { teaching environment } \\
\text { - } \\
\text { cotivational factors such as monetary incentives and } \\
\text { career progress \& career progress }\end{array}$ \\
\hline
\end{tabular}

This table depicts various factors which teacher researchers believed that they could affect research quality in HEIs in Oman. Having summarized these factors, it is quite evident that the institutional factors are really important in sustaining quality research produced by teacher researchers in HEIs in Oman. Because if the HEIs value research and support teacher researchers to carry out research, this would definitely encourage teachers to produce research with high quality.

\subsection{Summary of Key Suggestions for Promoting Quality Research in HEIs in Oman}

There are key suggestions from the findings which can be summarized to promote quality research in higher education institutions (HEIs) in Oman. Firstly, academic staff members should be trained on research-related issues such as how to conduct research and what makes quality academic research. Secondly, research infrastructure and policies should be improved and link research production and publication with career promotion. Thirdly, research culture and community should be established within the HEIs by creating a nexus between research and teaching. Fourth, academic staff members should be encouraged to participate in regional, national and international research and provide financial and administrative support and funds. Fifth, research based learning and teaching environment should be created which would help teacher researchers to be engaged in research activities. Sixth, international existing models should be adopted to evaluate current research quality within Omani HEIs. Seventh, HEIs need to have tailored policies of international standards with regard to quality research. Eighth, HEIs need to adopt a reward system for staff to encourage research and publications. Finally, research should be embraced as an integral part of the teaching practice and professional development, career growth and research should underpin the teaching and learning process.

\section{Limitations, Recommendations \& Conclusions}

This study has several limitations which are worth mentioning. Firstly, the number of participants is only 20. Secondly, only a survey as a primary tool along with literature review as a secondary tool were used for data collection, a study with a wider scope and more participants and tools may yield more broadly representative results. Based on the free responses from the teacher researchers, the study offers some recommendations for decision-makers and academic research departments to consider. Academic research and publications should be valued and should be linked to promotion and financial rewards. Moreover, quality research should inform teaching because teaching and research nexus is of utmost importance in HEIs. Additionally, research resources should be made available such as books, journals, software, etc. Further, staff members should be trained on research publications-related skills. The study 
concludes that quality research can only be promoted and sustained through using international paradigms for assessing research and addressing all the factors whether institutional, international or logistic in HEIs in Oman.

\section{References}

Adams, J. (2009). The use of bibliometrics to measure research quality in UK higher education institutions. Research Quality in Higher Education Institutions, 57, 19-32. doi: 10.1007/s00005-009-0003-3

Brennan, J., \& Teichler, U. (2008). The future of higher education and of higher education research. Higher Education, 56, 529-264. doi: 10.1007/s10734-008-9124-6

Cabral, A., \& Huet, I. (2014). Assessment of research quality in higher education: contribution for an institutional framework. Procedia- Social Behavioral Sciences, 116, 1528-1532. doi:10.1016/j.sbspro.2014.01.429

Chang, D., Nyeu, F., \& Chang, H. (2014). Balancing quality and quantity to build research universities in Taiwan. Higher Education. doi:10.1007/s10734-014-9841-y

Chou, C. (2008). The impact of neo-liberalism on Taiwanese higher education. The Worldwide Transformation of Higher Education International Perspectives on Education and Society, 9, 297-311.

Furlong, J. \& Oancea, A. (2005). Assessing quality in applied and practice-based educational research: a framework for discussion. Oxford University Department of Educational Studies.

Hattie, J., \& Marsh, H. W. (1996). The relationship between research and teaching. Review of Educational Research, 66, 507-542. doi: 10.3102/00346543066004507

Higher Education Funding Council for England (HEFCE) (2008). Research Assessment Exercise 2008: the outcome. Bristol: HEFCE.

Haustein, S., \& Lariviere, V. (2015). The use of bibliometrics for assessing research: possibilities, limitations and adverse effect. In. Welpe, J. Wollersheim, S. Ringelhan, \& M. Osterloh (Eds.), Incentives and Performance (pp. 1211391). Springer International Publishing.

Mahmood, S. (2011). Factors affecting the quality of research in education: students' perceptions. Journal of Education and Practice, 2, 34-40.

Mok, K. H., \& Wang, L. (2008). University governance reforms in China and Taiwan: Academic reflections. Paper presented at the Asia-Pacific Educational Research Association (APERA) Conference 2008, Nov. 26-28, NIE, Singapore.

Open Research Grant (ORG) Guidelines Manual. (2014). The Research Council, Sultanate of Oman.

Weingart, P. (2005). Impact of bibliometrics upon the science system: inadvertent consequences? Scientometrics, 62, 117-131. doi: 10.1007/s11192-005-0007-7

Wu, C. (2008). A critical review of challenges and opportunities for universities in Taiwan. In. A Strategic Network Promoting University Excellence (Ed.), mission and vision: development plan for world class universities and research centers of excellence. Taipei, Taiwan: National Taiwan University Press. 